\title{
Abordagem socioantropológica da surdez, Língua de Sinais e Educação Bilíngue: uma perspectiva histórica e cultural
}

\author{
Socio-anthropological approach to deafnees, Sign Language and \\ Bilingual Education: historical and cultural perspective
}

Márcia Cristina Barreto Fernandes de Abreu ${ }^{1}$

\begin{abstract}
RESUMO
O artigo apresenta aspectos relativos aos conceitos de Defectologia, da abordagem socioantropológica da surdez com o intuito de defender a tese de que o desenvolvimento da atividade simbólica na surdez demanda o acesso à Cultura Surda e a Língua de Sinais, características específicas da comunidade surda, sendo a família e a escola os espaços privilegiados para o desenvolvimento do pensamento e da linguagem nas pessoas surdas. Ao final analisaremos informações coletadas em entrevistas com uma estudante surda, Iara, de 13 anos, concluinte do Ensino Fundamental em uma escola pública que comprova a eficiência da Libras na constituição dos conceitos na pessoa.
\end{abstract}

Palavras-chave:

Abordagem socioantropológica da surdez. Defectologia. Desenvolvimento de conceito.

\begin{abstract}
The article presents aspects to the concepts of Defectology, socio-anthropological approach to deafness, defend the thesis the development of symbolic activity in deafness demands access to Deaf Culture and Sign Language, specific characteristics deaf community, family and school are privileged spaces for the development of thought and language in deaf people. And analyze information collected in interviews with a deaf student, Iara, 13 years old, concluding fundamental school in a public school, proves the efficiency of Libras in the constituition of concepts in the deaf.
\end{abstract}

Keywords: Socio-anthropological approach to deafness. Defectology. Concept development.

\section{Introdução}

A abordagem histórica e cultural compreende a construção do humano como processo no qual as transformações ocorrem na unidade; Humano-Cultura,

\footnotetext{
1 Psicóloga e Professora Adjunta da Universidade Federal de Uberlândia - Campus Pontal Ituiutaba. Graduada em Psicologia pela Universidade Federal de Uberlândia (1990), Mestre em Psicologia pela Universidade Católica de Brasília (2006), Doutora em Educação pela Faculdade de Educação da Universidade Federal de Uberlândia (2016). Orcid: https://orcid.org/0000-0001-95716682. E-mail: marciabarreto@ufu.br.
} 
mediados pela linguagem, o signo por excelência (VYGOTSKY, 1995). A atividade humana nos contextos sociais e culturais favorece o desenvolvimento das características, eminentemente, humanas e os processos psicológicos envolvem experiências em contextos sociais distintos. Sendo assim, a construção do humano está articulada com a maneira pela qual a sua imersão em uma determinada cultura o modifica de forma quantitativa e qualitativa. Existe uma grande variabilidade na forma e no conteúdo do desenvolvimento e aprendizagem, sendo uma delas as condições que caracterizam a constituição da pessoa com surdez.

Nessa perspectiva pretendemos apresentar aspectos relativos ao conceito de Defectologia proposto por Vygotsky (1995), da abordagem socioantropológica da surdez com o intuito de defender a tese de que o desenvolvimento da atividade simbólica na surdez demanda o acesso à Cultura Surda e a Língua de Sinais, características específicas da comunidade surda e sendo a família e a escola os espaços privilegiados para o desenvolvimento do pensamento e da linguagem para as pessoas surdas. Ao final analisaremos informações coletadas em entrevistas com uma estudante surda, Iara, de 13 anos, concluinte do Ensino Fundamental em uma escola pública da cidade de Uberlândia - MG que comprova a eficiência da Libras na constituição dos conceitos da pessoa com surdez.

\section{A Defectologia de Vygotsky}

Com a teoria marxista foi possível compreender as mudanças, as transformações sociais e pessoais como processos sociais, econômicos e políticos. Resultado das contradições lutas e conflitos sócio políticos. A abordagem histórico-cultural proposta nas teorias de Vygotsky (1999) possui a matriz marxista e procura o entendimento dos fatos vinculados a humanidade, historicamente, determinados pela materialidade da atividade, atuando sobre a natureza externa e modificando-a, o ser humano modifica a sua natureza interna.

Em 1925 Vygotsky fundou o laboratório de Psicologia para crianças com déficits e deficiências, do qual originou o Instituto Experimental de Defectologia. Suas contribuições foram teóricas, metodológicas, institucionais e clínicas. Entre suas metas estava o desejo de capturar a organização das funções psicológicas a das 
condutas, a defectologia é um termo russo utilizado para designar uma disciplina que estuda a desvantagem das pessoas que apresentam algum tipo de déficit. A defectologia defende a tese de que a criança cujo desenvolvimento se mostra “complicado" por um defeito, apresenta uma maneira peculiar de desenvolvimento (VYGOTSKY, 1995). A atipicidade a que se refere a defectologia não desconsidera a maturação orgânica, porém a secundariza, ao se apoiar na determinação social como a referenciadora dos processos mentais superiores do sujeito. As aquisições, especificamente, humanas são realizadas pela atividade prática, mediadas pela linguagem, pela interação com os outros e com o meio (SILVA, 2004).

No desenvolvimento complicado por um déficit, um fator importante, a se considerar, é a influência orgânica do processo de constituição da personalidade-subjetividade. O déficit, por uma parte, é uma limitação, uma diminuição da possibilidade do desenvolvimento. Precisamente na origem das dificuldades, o defeito estimula um movimento elevado e intensificado de desenvolvimento, caracterizando a lei da compensação, que possui caráter orgânico, involuntário e como qualquer processo de vencimento e luta pode ter dois resultados: a vitória e a derrota, entre os quais se dispõem as graduações possíveis (VYGOTSKY, 1995). Outro aspecto relevante apresentado pelo autor é lei da supercompensação, que possui caráter sociopsicológico, voluntário e determinado por duas forças: as exigências sociais implantadas no desenvolvimento da educação e as forças íntegras da psique humana. A supercompensação está relacionada à condicionalidade social de desenvolvimento da com déficit, compreendendo questões relativas à organização do coletivo, do movimento, da educação sociopolítica e da educação escolar para a formação da personalidade/subjetividade. A perspectiva histórico-cultural valoriza o trabalho da escola, entendendo que é necessário tecer um olhar e uma prática reformulada, para que, de fato, seja realizado um atendimento de qualidade para a promoção do desenvolvimento dos alunos que foram focos do estudo na defectologia.

A conduta coletiva (VYGOTSKY, 1995) não só ativa e exercita as funções psicológicas, como também é fonte do surgimento de novas formas de conduta, 
daquelas que surgiram no desenvolvimento histórico da humanidade e, que, na formação do sujeito se apresentam como funções psicológicas superiores: linguagem, pensamento, memória.

Ao nascer a criança surda não encontrará em seu meio condutas culturais de atividades adequadas, o que dificultará o seu processo de desenvolvimento histórico cultural. Vygotsky (1995) considera o desenvolvimento psicológico humano como aspiração em ocupar uma determinada posição relativa a uma lógica inerente à sociedade humana. Uma aspiração que se desenvolve como necessidade objetiva, como cadeia de ações planificadas pela exigência da adaptação social, denominada de psicologia de posição. Nessa perspectiva, o desenvolvimento psicológico parte da posição social (lócus social) que o sujeito vai ocupar na sociedade.

O planejamento de exigências sociais para o desenvolvimento e a conversão em uma unidade social determinada, isto é, a criação de um lócus social para a pessoa surda oferecerá condições para que se desenvolvam as suas capacidades, no coletivo está a fonte do desenvolvimento das funções psicológicas superiores. A surdez está contextualizada e marcada pelas condições materiais da vida social.

\section{3- A abordagem socioantropológica da surdez}

Tomando como referência a definição médica biológica da surdez, observamos que a Organização Mundial da Saúde (OMS) classifica a perda auditiva nos seguintes graus: 1) perda leve, de $26 \mathrm{~dB}$ a $40 \mathrm{~dB}$; 2) perda moderada, de $41 \mathrm{~dB}$ a $60 \mathrm{~dB}$; 3) perda severa, de $61 \mathrm{~dB}$ a $80 \mathrm{~dB}$ e 4) perda profunda, maior que $81 \mathrm{~dB}$. Com relação às características da perda auditiva, a OMS classifica três tipos: 1) perda condutiva, quando existe uma alteração na condução aérea do estímulo sonoro pela orelha externa ou média; 2) perda neurossensorial, quando ocorre uma perda de células ciliadas da cóclea e/ou nervo auditivo, afetando a percepção de diversos sons e comprometendo assim a percepção do estímulo sonoro; 3) perda mista, quando ocorrem alterações na orelha externa e/ou na orelha média e na orelha interna. Porém, faz se necessário uma leitura que supere essa perspectiva biológica, levando em consideração a influência dos 
contextos sociais e culturais em que a pessoa surda se insere, bem como a experiência singular com a surdez (OMS, 2007).

Skliar (1998) chama a atenção para o fato de que, quando se toma apenas a perda auditiva como referência para o entendimento da surdez, cria-se uma suposição de que os surdos formam um grupo homogêneo, cujas possíveis subdivisões devem responder à classificação médica das deficiências auditivas. Esse erro conduz à crença de que toda problemática social, cognitiva, comunicativa e linguística dos surdos depende, por completo, da natureza e do tipo do déficit auditivo, sem considerar as variáveis da dimensão social, tais como: o tipo de experiência educativa dos sujeitos, a qualidade das interações comunicativas e sociais em que participam desde a tenra idade, a natureza da representação social da surdez de determinada sociedade e a língua de sinais na família e na comunidade de ouvintes em que vive.

Nos trabalhos de Skliar (1998), Quadros (2004) e Sá (2006), encontra-se a concepção denominada "visão socioantropológica da surdez". Segundo esse conceito, os surdos constituem um grupo minoritário de pessoas que se agrupam para discutir e opinar sobre suas vivências pelo fato de serem seres visuais; a língua de sinais permite a comunicação e a interpretação de suas histórias e culturas. Prova disso é a forma como, mesmo com a proibição do uso de sinais durante o domínio da proposta oralista, a comunidade surda conseguiu uma forma de organização que permitiu o desenvolvimento e a ampliação da língua de sinais no mundo inteiro.

Nessa direção, a surdez é entendida como uma diferença cultural e linguística, que abrange significação política, de modo a ser construída histórica e socialmente. A visão socioantropológica da surdez tem em Skliar (1998; 1999) o seu principal difusor. Nela, o autor apresenta uma ideologia diferente da visão clínica, abordando o paradigma social, cultural e antropológico da surdez e aprofundando os conceitos de "bilíngue" e "bicultural". Nessa concepção, a criança surda precisa adquirir a primeira língua de sinais de seu país - no caso do Brasil, a Libras e, por meio dela, desenvolver a sua capacidade da linguagem e do pensamento, como suporte para acessar uma segunda língua, no caso, a língua 
portuguesa. Na visão socioantropológica, a surdez é vista como uma diferença cultural e linguística. Na direção da surdez como uma diferença linguística, será defendida a concepção do surdo como sujeito que desenvolve a sua atividade simbólica, mediado pela Língua de Sinais.

\section{Língua de Sinais}

Quadros e Karnopp (2004) defendem a concepção estruturalista da linguística enunciada por Chomsky (1986). A linguística é a ciência da linguagem que trata a língua como essência da linguagem. Língua, por sua vez, é concebida por essa ciência como um conjunto de signos abstratos, presentes na mente como resultado da história e da cultura dos grupos sociais. Partindo dessa concepção, as autoras apontam que os seres humanos podem fazer uso de uma língua de acordo com a sua modalidade de percepção e de produção. Como exemplo pode-se citar a modalidade oral auditiva e a modalidade viso-espacial. $\mathrm{Na}$ língua de sinais, que é uma língua de modalidade viso-espacial, são empregados, como meio de comunicação, movimentos gestuais e expressões faciais que são percebidos pela visão. Na língua oral, que é uma modalidade oral-auditiva, faz-se uso de sons articulados que são percebidos pelos ouvidos.

Quadros e Karnopp (2004) compartilharam também o conceito de língua enunciado por Chomsky (1986), segundo o qual a língua é um sistema que pode ser analisado considerando-se duas perspectivas: a língua externa e a língua interna. A língua externa se caracteriza como instâncias da linguagem externalizada, ou seja, eventos de fala atuais e potenciais, por exemplo, na gramática convencional, que se configuram como um conjunto de descrições da língua externa. A língua interna se define como a noção de estrutura, como parte da sentença estável. A noção de estrutura nos remete a um elemento da mente da pessoa que conhece a língua que foi adquirida e é usada sistematicamente.

Quadros e Karnopp (2004), em consonância com Chomsky, apontam que os principais traços atribuídos às línguas são: a flexibilidade e versatilidade; arbitrariedade; descontinuidade; criatividade e produtividade; dupla 
articulação; padrão; dependência estrutural. A flexibilidade se relaciona às múltiplas funções de comunicação da língua (expressar emoções, afirmar, perguntar, referir ao passado, ao presente, ao futuro). A arbitrariedade se relaciona com a conexão arbitrária entre forma e significado. A descontinuidade se opõe à variação contínua, visto que mesmo as palavras que apresentam uma diferença mínima na forma podem ter significados bem distintos. A criatividade e produtividade oferecem a propriedade que possibilita a construção e interpretação de novos enunciados. A dupla articulação relaciona-se ao fato de os fonemas não terem significado isoladamente, mas se estabelece na combinação de dois ou mais fonemas. Segundo essa concepção, a língua teria uma organização em duas camadas: a camada dos sons, que se combinam em uma camada de unidades maiores. O padrão se refere a uma rede de elementos interligados, na qual cada item deve ser mantido em determinado local, conforme a sua relação com os outros. Por fim, a dependência estrutural, que consiste em uma língua ter estruturas dependentes que possibilitam um entendimento da estrutura interna de uma sentença.

Com base nesses pressupostos, os pesquisadores Stokoe (1960) e Quadros \& Karnopp (2004) estudaram a estrutura da língua de sinais, analisando as partes constituintes dos sinais. Concluíram que essa linguagem atendia aos critérios linguísticos de uma língua, no que se refere ao léxico, à sintaxe e à capacidade de gerar uma quantidade infinita de sentenças. Sendo assim, as línguas de sinais compartilham uma série de características que permitem atribuir-lhe o caráter específico de uma língua. Portanto, a língua de sinais é considerada um sistema linguístico legítimo.

Os estudos de Sá (2002), Strobel (2009) e Quadros e Cruz (2011) mostraram que as línguas de sinais são adquiridas pelos surdos com e rapidez, possibilitando o acesso a uma linguagem que permite uma comunicação eficiente e completa, tal como aquela desenvolvida por sujeitos ouvintes. Isso também permitiria ao surdo um desenvolvimento cognitivo e social muito mais adequado, compatível com sua faixa etária. 


\section{A linguagem na perspectiva histórica e cultural: o desenvolvimento do signo e do conceito e a pessoa surda}

A mediação simbólica pode ser considerada como unidade: enquanto prática social que categoriza a realidade, refletindo-se em um sistema de signos e no nível individual no qual exerce o papel mediador na função planejadora e orientadora do pensamento através do discurso interior (LURIA, 1991; 2001). A atividade e a mediação são aspectos fundamentais em qualquer processo de desenvolvimento humano. É a mediação que possibilitará às experiências serem interpretadas, internalizadas e, portanto, se tornarem significativas para as pessoas. Dessa forma, pode-se afirmar que a experiência da realidade, a identidade e os fenômenos psicossociais se constituem na e pela linguagem. Seu significado é, ademais, inseparável do contexto interacional no qual ela é gerada. Significar é essencialmente, um processo mental, consciente, contínuo, dinâmico, interativo e intersubjetivo e tem a ver com a representação (memória) que se faz do conhecimento.

O processo de desenvolvimento dos signos é aspecto fundamental da constituição do pensamento e da linguagem no humano. $\mathrm{O}$ desenvolvimento do pensamento e da linguagem depende da experiência social e do domínio dos meios sociais do pensamento, isto é, da linguagem enquanto mediadora. As relações entre o pensamento e a linguagem surgem e se constituem no processo de desenvolvimento histórico da consciência humana, sendo a consciência e a possibilidade de comunicação pela linguagem, uma produção fundamental da história social da humanidade (VIGOTSKI, 1991). Os processos de pensamento e linguagem revelam unidade, mas não identidade. A atividade mental realiza-se por meio de significações, sentidos, enfim a internalização de signos.

A constituição dos signos perpassa quatro estágios básicos: o primeiro é chamado de estágio natural ou primitivo, apresentando como características a linguagem pré-intelectual e o pensamento pré-verbal. O segundo estágio corresponde à chamada psicologia ingênua, no qual a criança experimenta as propriedades físicas do seu próprio corpo e dos objetos à sua volta e aplica essa experiência na utilização de instrumentos, caracterizando o primeiro exercício da 
inteligência prática. O terceiro estágio caracteriza-se pela utilização de signos externos (operações externas) que são utilizados como auxiliares na solução de problemas internos. O quarto estágio é denominado de crescimento de fora para dentro (signos internos). As operações externas se interiorizam e passam por uma profunda mudança. A pessoa começa a operar mentalmente, a usar a memória lógica, a operar com relações interiores, em forma de signos interiores. Em relação à fala, corresponde à linguagem interior ou silenciosa. O desenvolvimento da linguagem interior depende de fatores externos. $\mathrm{O}$ desenvolvimento da lógica é uma função direta da sua linguagem socializada. $\mathrm{O}$ desenvolvimento do pensamento depende de seu domínio dos meios sociais do pensamento, isto é, da linguagem. Existe uma interação-unidade constante entre as operações externas e internas, uma se transformando na outra (VIGOTSKI, 2001).

A construção do conceito e um ato de generalização, um ato real e complexo de pensamento que requer o desenvolvimento de processos psicológicos complexos, tais como: atenção arbitrária, memória lógica, abstração, comparação discriminação (VIGOTSKI, 2001). O processo de formação do conceito significa o processo de constituição do pensamento. Sendo a linguagem e o pensamento mutuamente constituídos, a lei geral que norteia o desenvolvimento das funções superiores é o princípio fundamental para compreender a construção do conceito. A palavra ou o sinal em Libras (linguagem) representam o signo por excelência, são mediadores, é impossível pensar em desenvolvimento da atividade simbólica fora do mundo cultural e sem o uso da linguagem. A formação do conceito se organiza a partir de três os estágios do desenvolvimento propostos por VIGOTSKI (2001). O primeiro estágio é chamado de amontoados e se caracteriza pela formação de uma pluralidade não ordenada, a discriminação de um amontoado de objetos que não possuem um fundamento interno suficiente. O segundo estágio é denominado pensamento por complexos. A partir do funcionamento do pensamento verbal, as ligações entre os objetos tornam-se concretas e factuais, descobertas por meio da experiência direta. Nele, o significado da palavra refere-se aos mesmos objetos, existe uma identidade de referentes. 
No entanto, a criança utiliza operações mentais diferentes para pensar sobre o mesmo objeto. A utilização do mesmo referente garante a compreensão entre quem ensina e quem aprende, não havendo coincidência quanto aos significados. No terceiro estágio, dos conceitos propriamente ditos ou conceitos "verdadeiros", o aprendiz isola e abstrai os atributos dos objetos na totalidade da experiência concreta de que fazem parte, num movimento de análise e síntese. Essas operações intelectuais são dirigidas pelo uso da palavra ou dos sinais, em Libras (VIGOTSKI, 2001).

A criança ouvinte desde seu nascimento é exposta à língua oral, dessa forma é fornecida para ela a oportunidade de adquirir uma língua, a qual irá permitir realizar trocas comunicativas, vivenciar situações do seu meio e, assim, possuir uma língua efetiva e constituir a sua aprendizagem e desenvolvimento. Para a criança surda deveria ser dada a mesma oportunidade, de adquirir uma língua própria para constituir sua linguagem. Nesse sentido pode-se defender a perspectiva de educação bilíngue na área da surdez como a possibilidade de antecipar a consciência dos próprios surdos, através da significação do mundo, incluindo o significado da surdez, o que há bem pouco tempo acontecia somente na idade adulta. É importante considerar que a aprendizagem da língua de sinais, depende da mediação do outro social para a sua constituição (a família e a escola).

A escola é considerada um espaço formal de promoção de ensino e aprendizagem das pessoas desde a mais tenra idade. Nesse sentido tem a importante função de garantir processos formativos que contribuam efetivamente com a socialização e com a participação social dos alunos em qualquer fase da vida, mas, em especial, das crianças e dos adolescentes. O redimensionamento da escola deve promover a matrícula e o efetivo atendimento pedagógico, no sistema regular de ensino, para uma parcela de alunos surdos.

$\mathrm{Na}$ defesa dessa concepção da surdez como diferença cultural e, principalmente, linguística, apresentaremos uma entrevista semiestruturada com a estudante surda, Iara (nome fictício para preservar a identidade da participante), de 13 anos, concluinte do Ensino Fundamental em uma escola pública da cidade de Uberlândia, Minas Gerais. A estudante fez parte do grupo 
de participantes da pesquisa realizada para a elaboração da tese de Doutorado: A constituição de surdos em alunos no contexto escolar: conflitos, contradições e exclusões (ABREU, 2016).

A entrevistas semiestruturada, no estudo citado, tive como objetivo de explorar aspectos da subjetividade da experiência escolar da estudante, ambiente da presente pesquisa. As entrevistas ocorreram como uma conversa, favorecendo o desenvolvimento e a explanação das informações pertinentes, um momento de interação entre a pesquisadora, a aluna surda e a intérprete. A entrevista semiestruturada foi autorizada pela assinatura do Termo de Consentimento Livre e Esclarecido (TCLE) assinados pela participante e/ou seus respectivos responsáveis, por ser, no caso, menor de idade.

As informações coletadas acerca da percepção da surdez ofereceram algumas pistas em relação à singularidade da construção simbólica da pessoa surda pesquisada, enquanto sujeito de linguagem e nos remete às suas vivências do surdo em um mundo ouvinte em uma escola "de ouvintes". As questões da entrevista foram utilizadas na tentativa de reconstrução de aspectos subjetivos sobre aa suas atividades escolares, vinculando-as às práticas escolares para as pessoas surdas, orientadas para que tenham uma abordagem bilíngue.

A primeira entrevista constou de questões vinculadas às duas dimensões, sendo a primeira o contexto familiar e a segunda o contexto escolar. A respeito da primeira dimensão, as questões buscavam informações acerca do ambiente familiar na infância, percepção da surdez, contato com L1 (Libras) e L2 (Língua Portuguesa) e os tipos de atendimento escolar e clínico recebidos pela estudante. $\mathrm{Na}$ segunda dimensão foram elencadas questões, as quais abrangeram as características do contato com o ambiente escolar, características da comunicação na escola, características da aprendizagem de Libras e dos conteúdos escolares.

As entrevistas com a Iara foram realizadas com a colaboração de uma intérprete (ouvinte) de Libras, garantindo assim a valorização da experiência da Iara com a sua primeira língua (L1) a Libras. 


\subsection{Iara: a cultura surda vai à escola}

$\mathrm{Na}$ época da entrevista Iara contava 13 anos de idade e cursava o 8. ${ }^{\circ}$ ano do Ensino Fundamental. Adquiriu a surdez em consequência de herança genética. Na família nuclear de Iara todos são surdos: pai, mãe e irmão.

O convívio com a surdez faz parte do cotidiano da família de Iara, tanto que todos são proficientes em Libras. Essa característica da comunicação da família permitiu à menina que tivesse Libras como sua primeira língua.

A família de Iara, sabedora da importância do contato da criança surda com professor surdo, ou mesmo um professor ouvinte que soubesse Libras, foi bastante seletiva ao escolher a primeira escola para a filha. $\mathrm{O}$ primeiro professor de Iara era ouvinte, porém proficiente em Libras. Todo o processo de escolarização da menina foi acompanhado pela família, que cobrou um atendimento que valorizasse a Libras, com um professor que fosse proficiente em Libras, bem como um intérprete. Iara não entra na estatística da distorção idadesérie $^{2}$, o que nos leva a refletir que, para o aluno surdo ter uma experiência escolar satisfatória, a Libras deve ser reconhecida, ensinada e valorizada a fim de favorecer o desenvolvimento da atividade simbólica na pessoa surdas.

\subsection{Percepção da surdez}

A aluna surda narra a experiência vivenciada em seu primeiro enfrentamento da condição de surdez, que é a percepção dela como surda, bem como os desdobramentos da tomada de consciência de ser surdo na família e na escola.

Ao ser questionada sobre a sua idade quando percebeu a sua surdez, Iara nos conta que:

Na verdade eu não lembro quando eu percebi. Eu conversava em Libras. Todo mundo sabe Libras.

\footnotetext{
2 Pela legislação que organiza a oferta de ensino no país (Lei n. ${ }^{\circ}$ 9.394/1996), a criança deve ingressar aos 6 anos no $1^{\circ}$ ano do ensino fundamental e concluir a etapa aos 14 anos. O valor da distorção é calculado em anos e representa a defasagem entre a idade do aluno e a idade recomendada para a série que ele está cursando. $\mathrm{O}$ aluno é considerado em situação de distorção ou defasagem idade-série quando a diferença entre a idade do aluno e a idade prevista para a série é de dois anos ou mais (BRASIL, 1996).
} 
Ter nascido em uma família de surdos fluentes em Libras possibilitou a Iara que o processo de linguagem e pensamento se constituísses mediados pela Libras, língua utilizada pelo outro (família). A experiência vem com uma construção do conceito de que todo mundo é surdo, todo mundo sabe Libras, enfim, de que a Libras era uma língua universal.

Ainda sobre percepção da surdez, perguntamos a Iara se houve algum momento, em sua infância, em que ela se percebera surda:

Na idade de 4-5 anos que eu comecei a perceber...

Bom! Quando eu ia bater papo, então parecia que eu queria trocar, eu queria ser o ouvinte. Eu percebia que eu era diferente, que eu era surda. Eu não conseguia comunicar muito bem...

A percepção da surdez em Iara se deu aos 05 anos e, à medida que ela foi saindo de casa e convivendo com pessoas ouvintes, ela percebeu a sua surdez, ao notar que a sua língua primeira língua (Libras) não servia para se comunicar com um grande número de pessoas. Parece que a convivência no ambiente escolar, com crianças surdas e ouvintes, não proficientes em Libras, foi fundamental para a percepção dessa diferença. A percepção da diferença cultural entre surdos e ouvintes veio pelo contato com a cultura ouvinte, pela dificuldade de comunicação que, enfim, rompeu o conceito de que todos sabiam Libras.

Outro aspecto a ser considerado no dizer de Iara é sua vontade de se tornar ouvinte para melhor se comunicar. Expressa uma valorização da forma como a maioria ouvinte comunica. Se eu não me comunico bem e quero ser ouvinte, então parece que a comunicação nos ouvintes é melhor, tem mais valor que a comunicação dos surdos, já que a parcela de ouvintes na sociedade é maior, cultura majoritária e dominante. Transparece aqui a ideia de que estar no mundo como ouvinte é melhor que estar no mundo como surdo.

Ao adentrar no mundo ouvinte, Iara começa a perceber que ela era surda e que isso a tornava diferente. Essa diferença foi bastante marcada no fato de ela perceber uma dificuldade de comunicação com os ouvintes. Na relação Libras e Língua Portuguesa, a Língua Portuguesa acaba sendo uma língua desejada por fazer parte da 
comunicação da parcela majoritária da população que é ouvinte. Iara demonstra uma identificação com o ideário dos ouvintes com os quais convive.

\subsection{Práticas escolares inclusivas para as pessoas surdas: entre o dito e o não dito}

Propõe a discussão da tensão que se estabelece entre o que está presente nos documentos que prescrevem teórica e legalmente o atendimento educacional de surdos e o relato das experiências vivenciadas nas práticas escolares, às quais são submetidos os alunos surdos na escola. Esse eixo se desdobra em dois subeixos: 2.1 Comunicação com a família e 2.2 A escola e o primeiro contato com a escola.

\subsubsection{Comunicação com a família e na escola}

Quando perguntada sobre a sua comunicação com a escola e a família, Iara nos diz:

Quando eu era criança, eu já nasci surda. Papai e mamãe também eram surdos. Nós nos comunicávamos muito bem, então foi muito fácil.

A vivência de Iara com sua família surda, com predomínio da cultura surda e da utilização da Libras possibilitou que a comunicação fosse bem desenvolvida entre eles. $\mathrm{O}$ fato de todos falarem compartilharem a cultura surda e a mesma língua possibilitou que Iara tivesse bem constituída a sua atividade simbólica: os signos e os conceitos. Um processo que para ela parece ter sido fácil, acessível, simples e descomplicado. Tal fato demonstra que a relação facilitada com Libras, proporcionada pela convivência e adesão da família à aprendizagem de Libras que trouxe repercussões positivas em sua vida escolar.

Sobre as características da comunicação da Iara com os colegas na escola. Ela relata:

Tinha amigos, sim, mas eu tinha que escrever, porque eu tinha amigos ouvintes. Ầs vezes ensinava Libras para eles, às vezes escrevia. E a gente ia se comunicando. 
Revela-se o fato de Iara conviver no ambiente escolar com crianças surdas e crianças ouvintes e que, para melhorar a comunicação, utilizava-se da escrita. $\mathrm{O}$ surdo bilíngue, que tem conhecimento da língua portuguesa, pode se comunicar com o colega e com o professor ouvinte por meio da escrita de bilhetes, uma prática ainda comum, entre ouvintes que não conhece a Libras e surdos com proficiência em língua portuguesa.

O fato de Iara estar disponível para ensinar Libras, mesmo reconhecendo que a língua portuguesa é usada pela maioria da população escolar, denota uma vontade de fazer com que a Libras seja uma língua mais conhecida e usada. Acreditamos que isso ocorra pela constituição psíquica promovida pelo uso de Libras e do valor positivo atribuído a Libras na sua família surda.

Ainda falando da comunicação com os colegas na escola, Iara conta:

Preciso do intérprete para entender. Mas junto com o surdo, quando estou estudando em grupo, só com surdo, fica mais fácil. Fica mais rápido aprender.

Mesmo tentando uma comunicação com os ouvintes, às vezes, há uma dificuldade de comunicação entre surdos e ouvintes na escola, que precisa ser mediada pelo intérprete. Os surdos sabem Libras e se comunicam em Libras. Os ouvintes sabem a Língua Portuguesa e se comunicam, principalmente, pela oralização. Em suas palavras, Iara sugere que a relação entre surdos e ouvintes, na escola, não é tranquila, é uma relação que causa conflito.

\subsubsection{Primeiro contato com a escola}

Ao responder o questionamento sobre o seu primeiro contato com a escola, Iara diz:

Meu professor sabia Libras. Meu primeiro professor sabia Libras.

Os alunos (surdos) a partir da segunda série tinham intérprete, e os estudos transcorreram bem. 
Os pais de Iara, ao procurar atendimento escolar demostraram ter consciência da necessidade do contato de Iara com um professor surdo ou um professor ouvinte, proficientes em Libras, para seu processo de alfabetização. Segundo suas palavras, essa escolha resultou em sucesso, já que, desde o início de sua escolarização, vem alcançando um bom desempenho.

Ainda falando sobre sua primeira experiência escolar, Iara conta que:

$\mathrm{Na}$ escola da prefeitura era inclusão. Foi normal a minha vida escolar. Foi normal. Eu desenvolvia tranquilamente nos estudos.

Iara faz uso da palavra inclusão para caracterizar o modelo de atendimento oferecido na escola regular, o atendimento do intérprete educacional, que marca um traço da educação bilíngue e na perspectiva da inclusão escolar: "Na escola da prefeitura era inclusão". Essa fala de Iara traz uma construção social baseada em documentos e leis que orientam e prescrevem, desde a década de 1990, a abordagem inclusiva no atendimento das crianças surdas. Mesmo vivenciando as práticas escolares que não são inclusivas, percebe-se que os documentos e as leis influenciam o discurso da escola, levando o aluno a construção de um conceito da inclusão como algo que efetivamente ocorre no ambiente escolar.

No caso da educação bilíngue para surdos de grupo social minoritário, pode-se considerar que ela já apresenta problemas ao destinar-se a esse grupo pelo fato de ser quantitativamente menor em relação aos ouvintes e, também, por serem considerados uma minoria, pelo fato de não apresentar, socialmente, o mesmo poder que o grupo ouvinte mantém. Essa característica se reflete no trabalho da escola com os alunos surdos, quando prioriza em seu trabalho pedagógico a língua portuguesa em detrimento da Libras.

\subsubsection{Prática escolar atual: características do trabalho pedagógico dos professores} e do intérprete de Libras

Ao falar das disciplinas e conteúdos trabalhados na escola, dos quais ela gosta, Iara diz: 
Sempre ele (professor de inglês) dá um trabalho. A gente treina, faz a lista de exercícios, faz tradução do inglês para o português. Do português para o inglês. Na prova também, os exercícios são muitos legais. Eu gosto da aula de inglês.

É possível que a motivação que sente pelo aprendizado de outras línguas advenha da vivência em um ambiente bilíngue, principalmente no seio da família, lugar em que surdos e ouvintes têm uma convivência harmoniosa, no que tange à comunicação.

Ao falar sobre a disciplina e os conteúdos da escola, Iara apresenta a matemática como uma disciplina difícil de aprender, relatando o seguinte:

É preciso explicar mais... matemática é livro. Por mais que explica.... Parece que a hora que explica e vai fazer os exercícios é muito difícil... Eu sinto uma dificuldade maior em aprender os conteúdos...Você lê, copia o exercício, responde. Falta mais explicação. Fica difícil para você perceber... Se explicasse mais seria mais fácil de compreender o conteúdo. Faz um exercício, passa para o outro sem fazer a ligação de um com o outro, aí fica mais difícil compreender o conteúdo.

Quando Iara fala "matemática é livro" está explicitando a dificuldade que o professor tem de relacionar o conteúdo da matemática com a vida cotidiana. Relata que o professor não consegue demonstrar para o aluno o quanto essa disciplina é importante para compreendermos conteúdos simples e também os conteúdos mais complexos. O modelo de prática pedagógica utilizado pelo professor de Iara é muito tradicional. Iara denuncia que a forma como é ensinada a matemática não consegue fazer com que os alunos entendam a ligação de um conteúdo com o outro, enfim está fragmentada. E a falta de conexão dos conteúdos com um uso prático a distância mais ainda da possibilidade de adquirir o seu conhecimento.

Iara faz uma crítica sobre as características da prática escolar e traz para si, em função da surdez, a responsabilidade de não aprender quando diz:

Eu sinto uma dificuldade maior em aprender os conteúdos [...]. 
A prática escolar descrita pela aluna em sua experiência escolar leva a uma reflexão de que esse problema não é vivenciado apenas pelo aluno surdo. A qualidade ou a falta de qualidade da maneira como o professor trabalha as disciplinas e os conteúdos parece estar afetando a aprendizagem de todos os alunos envolvidos (alunos surdos e alunos ouvintes).

Ao falar da sua relação com o intérprete educacional e do papel do intérprete em seu acesso aos conteúdos escolares, temos:

Converso com o professor, mas sempre preciso pedir ajuda para intérprete. Chamo o intérprete para explicar o que eu quero. Aí... por exemplo do conteúdo. Aí o intérprete fala assim... Eu chamo o intérprete e peço para perguntar para o professor como é isso aqui, para o professor poder me falar... Sempre o intérprete está interferindo nessa relação. É muito difícil... Todas as vezes que vou comunicar com o professor preciso da ajuda do intérprete.

$\mathrm{Na}$ sala de aula, eu preciso esperar o professor passar o conteúdo e depois o intérprete me passar. Isso demora. Até que eu tenha esse retorno eu acho demorado. Às vezes é ruim.

Eu gosto muito do intérprete. Porque aí há a comunicação na Libras, só que tem que ter paciência... O surdo gosta muito do intérprete... A minha vontade é que tivesse só a sala de surdo... Professores surdos porque não tinha essa de cortar conteúdo. Acho que seria mais fácil. Porque até que eu chamo o intérprete... O professor está falando.. O intérprete interpretando... É complicado... A aula demora mais. Agora, se fosse uma aula só para surdos e todos falassem Libras ... Teria um melhor aprendizado e desenvolveria melhor a dinâmica da sala de aula. Há uma perda de tempo até que o professor passa (o conteúdo) para o intérprete interpretar... Então não tem essa comunicação direta com o professor. Se todos usassem Libras seria mais fácil.

O trabalho do intérprete parece despertar em Iara um sentimento de ambivalência. As práticas escolares vivenciadas por ela, em que o intérprete aparece como uma espécie de único mediador entre a aluna surda e o conhecimento é marcada pelo gostar do intérprete e pela importância de o intérprete favorecer o acesso aos conhecimentos ensinados na escola. Em seus dizeres, há uma reivindicação indireta de uma aula, uma escola, que favoreça a aprendizagem de forma mais significativa. Mesmo reconhecendo a importância do 
trabalho do intérprete, a aluna percebe que as condições de seu trabalho não são favoráveis ao aprendizado. Iara parte dessa reflexão para expor a necessidade de aulas direcionadas a alunos surdos. A reivindicação de uma concepção de inclusão que necessariamente reconheça a diferença cultural e linguística, no caso da surdez, o que não se efetiva nas práticas escolares atuais.

Outro aspecto a considerar é percepção do tempo. Para Iara, o processo de constituição do conceito demanda um tempo que, para ela, é tido como "demorado, complicado, às vezes ruim", concluindo a interpretação (PortuguêsLibras) configura como uma perda de tempo: "Há uma perda de tempo". Eu diria de elementos que podem auxiliar na construção do conhecimento para os alunos surdos. Iara demonstra perceber que, para o intérprete, é muito difícil dominar todos os conhecimentos prescritos no currículo escolar. Pensando assim, ela tem razão ao dizer que a relação direta com o professor poderia favorecer um acesso mais aprofundado dos conteúdos escolares.

Com relação às abordagens de educação inclusiva e educação bilíngue (ambiente bilíngue), transparecem, nos dizeres de Iara, as seguintes considerações:

$\mathrm{Na}$ inclusão é muito difícil a comunicação. Porque nem todos sabem Libras. Professor vai explicar o conteúdo, e é difícil. Passa pelo intérprete, e o aluno surdo acha que a comunicação deve ser mais rápida com Libras. Isso combina. Se fosse ambiente bilíngue e todos soubessem Libras seria mais rápido. Se todos tivessem o mesmo olhar e soubessem Libras.

Eu quero ter ambiente bilíngue... Se fosse bilíngue o professor saberia Libras. Seria melhor. A experiência é de que, se no futuro existir uma escola bilíngue, tudo ia ser bem melhor. Eu quero ter uma escola bilíngue de verdade.

Mas eu sempre acho que surdo e ouvinte é importante para desenvolver um ambiente bilíngue.

Para a Iara a cultura surda a Libras e educação bilíngue são valorizadas em sua experiência pessoal e pode estar vinculada a uma convivência harmoniosa entre surdos e ouvintes em sua família. Porém, na escola de Iara a comunicação entre surdos e ouvintes está restrita ao trabalho do intérprete, não se configurando como educação bilíngue. 


\section{Considerações finais}

Todos os aspectos tratados no artigo tiveram a intencionalidade de defender a constituição do humano como processos de internalização das suas vivências em contextos históricos, culturais e sociais. A cultura altera de forma significativa os aspectos relativos ao desenvolvimento e aprendizagem humana e, no caso específico da surdez, a Língua de Sinais se configura como um signo, por excelência, com a mesma função da língua oral para as pessoas ouvintes. $\mathrm{O}$ estudo sobre defectologia busca compreender as possibilidades de construção do ser humano, marcado por um déficit, reflete de maneira explicita o movimento de modificação dos aspectos sociais e culturais (externos) e sua atuação nos processos psicológicos (internos). A defectologia se apoia na determinação social do sujeito como aquisições realizadas pela atividade do ser humano no mundo, pela convivência com os outros e pela mediação simbólica advinda dos instrumentos e signos, em especial, a linguagem (Língua).

A surdez marca a necessidade de uma reorganização social que favoreça o enfrentamento das dificuldades caudadas pelo déficit auditivo que podem ser atravessadas pela unidade: compensação- supercompensação. A compensação caracterizando um estímulo gerado pelo déficit que busca um movimento interno de origem orgânica, que busca a diminuição das limitações que a surdez pode causar. A supercompensação relacionas com a necessidade de alterações sociais e culturais para que se possa construir um lugar social favorável para o desenvolvimento possível das pessoas surdas. Os surdos não formam um grupo homogêneo, cujas possíveis subdivisões devem responder à classificação médica das deficiências auditivas. A problemática social, comunicativa e linguística do surdo não está condicionada natureza e do tipo de déficit auditivo, mas às formas de experiências educativas dos sujeitos; a qualidade das interações comunicativas e sociais em que participam desde a tenra idade; a natureza da representação social da surdez de determinada sociedade e a língua de sinais na família e na comunidade de ouvintes. 
O panorama histórico da surdez indica que o interesse de atendimento educacional das pessoas surdas nos remete ao século XVI, nesse período muitos estudos e métodos foram construídos, sendo que a história nos conta que dois deles foram os mais expressivos. $\mathrm{O}$ método getualista francês e o método oralista alemã. Apesar de no início haver uma convivência tolerada entre eles, o II Congresso Internacional sobre Educação de Surdos, em Milão (1880), definiu a proposta oralista como orientação para as práticas escolares, banindo das escolas o método de sinais os professores surdos que se comunicavam e ensinavas a linguagem gestual. A matriz oralista se tornou a única referência "legal" na educação de surdos, porém, ela não conseguiu com que a sua maioria, desenvolvesse os conceitos e pudessem se constituir como sujeitos de linguagem.

Mesmo com a proibição do uso de sinais durante o domínio da proposta oralista, a comunidade surda conseguiu se organizar para permitir o desenvolvimento e a ampliação da língua de sinais no mundo inteiro. E, a partir de 1960, a aposta passou a ser a de que a abordagem socioantropológica da surdez e a Língua de Sinais consigam um resultado mais efetivo na construção do pensamento e da linguagem do surdo.

A visão socioantropológica da surdez traz a compreensão de que os surdos constituem um grupo minoritário, que se agrupam para discutir e opinar sobre suas vivências utilizando os sinais, pelo fato de serem seres visuais. A língua de sinais permite a comunicação e a interpretação de suas histórias e culturas. Nessa direção, a surdez é entendida como uma diferença cultural e linguística, que abrange significação política, de modo a ser construída histórica e socialmente. Supera a ideologia da visão clínica e aborda o paradigma social, cultural e antropológico da surdez e apresenta os conceitos: "bilíngue" e "bicultural". A pessoa surda precisa ter acesso a uma língua de sinais como sua primeira língua (L1) e por meio dela desenvolver linguagem e pensamento.

Quadros e Karnopp (2004) compartilharam também o conceito de Língua enunciado por Chomsky (1986), segundo o qual a língua é um sistema que pode ser analisado considerando-se duas perspectivas: a língua externa e a língua interna. A língua externa se caracteriza como instâncias da linguagem 
externalidade, ou seja, eventos de fala atuais e potenciais, como também os sinais. A língua interna se nos remete a um elemento da mente da pessoa que conhece a língua que foi adquirida e é usada sistematicamente. A língua de sinais se caracteriza por ser uma língua de modalidade viso espacial, utilizando como meio de comunicação, os movimentos gestuais e as expressões faciais que são percebidos pela visão.

Os pesquisadores Stokoe (1960) e Quadros e Karnopp (2004) estudaram a estrutura da língua de sinais, analisando as partes constituintes dos sinais, concluindo que eles atendem aos critérios linguísticos de uma língua, no que se refere ao léxico, à sintaxe e à capacidade de gerar uma quantidade infinita de sentenças. Sendo assim, as línguas de sinais compartilham uma série de características que permitem atribuir-lhe o caráter específico de uma língua. Portanto, a língua de sinais é considerada um sistema linguístico legítimo.

Para além disso, os estudos de Sá (2002), Strobel (2009) e Quadros e Cruz (2011) mostraram que as línguas de sinais são adquiridas pelos surdos com e rapidez, possibilitando o acesso a uma linguagem que permite uma comunicação eficiente e completa, tal como aquela desenvolvida por sujeitos ouvintes. Isso também permitiria ao surdo um desenvolvimento cognitivo e social muito mais adequado, compatível com sua faixa etária.

Iara se configura como uma aluna que teve Libras como primeira língua e mediada pela cultura surda. Tal experiência a tornou uma referência na instituição escolar como alguém que, proficiente em Libras, tem uma atitude de cobrança em relação a uma melhoria da comunicação entre professor, aluno, intérprete e conhecimentos curriculares transmitidos pela instituição. Principalmente, no que tange à valorização da Libras como uma segunda língua para a comunidade escolar, como possibilidade de construção de um ambiente bilíngue na escola.

O relato da entrevista de Iara ajuda na compreensão da importância dos assuntos tratados no artigo, no que tange a compreensão as surdez como diferença cultural, linguística e as contribuições da abordagem histórica e cultural, bem como os aspectos da defectologia e o desenvolvimento dos conceitos no humano surdo, como referência para uma intensa busca de conhecimentos da teoria e da prática 
com o intuito da construção de um lugar social favorável ao desenvolvimento possível da pessoa surda, em especial, na família e na escola. De modo especial, a defesa do surdo como sujeito de linguagem e de que os sinais em Libras tem a função de signos, por excelência, na constituição dos conceitos na pessoa surda.

\section{Referências}

ABREU, M. C. B. F. A constituição de surdos em alunos no contexto escolar: conflitos, contradições e exclusões. 2016. 175f. Tese (Doutorado em Educação) Faculdade de Educação, Universidade Federal de 2016, Uberlândia, 2016. DOI: https://doi.org/10.14393/ufu.te.2016.60

ALVES, C. B. A. Educação especial na perspectiva da inclusão escolar: Abordagem Bilíngue na escolarização de pessoas com surdez. Ministério da Educação. Secretaria da Educação Especial. Brasília: MEC, 2010.

CHOMSKY, N. Knowledge of linguage, its nature, origin and use. New York: Praeger, 1986.

LACERDA, C. B. F. Um pouco da história das diferentes abordagens na educação dos surdos. Caderno CEDES, v 19, n. 46, 1998. DOI: https://doi.org/10.1590/s0101$\underline{32621998000300007}$

LURIA, A. R. Desenvolvimento cognitivo: seus fundamentos culturais e sociais (Trad. BARRETO, O, de A. e M.). Ícone. São Paulo. 1990.

LURIA, A. R. Pensamento e linguagem: as últimas conferências de Luria. Porto Alegre: ARTMED, 2001.

PETEAN, E. B. J.; BORGES, C. D. Deficiência auditiva: escolarização e aprendizagem de língua de sinais na opinião das mães. Paidéia, Ribeirão Preto, v. 12, n. 24, 2002. DOI: http://dx.doi.org/10.1590/S0103-863X2002000300008.

QUADROS, R. M.; CRUZ, R. R. Língua de sinais: instrumentos de avaliação. Porto Alegre: Artmed, 2011.

QUADROS, R. M.; KARNOPP, L. B. Lingua de sinais brasileira: estudos linguísticos. Porto Alegre: Artmed, 2004.

SÁ, N. A. L. Existe uma cultura surda? (Artigo). In: Cultura, poder e educação de surdos. São Paulo. Paulinas, 2006.

SACKS, O. Vendo Vozes: uma viagem ao mundo dos surdos. Trad.: MOTA, L. São Paulo. Cia da Letras, 2000. 
SKLIAR, C. A surdez: um olhar sobre as diferenças. Porto Alegre: Dimensão, 1998.

STROBEL, K. História da educação de surdos. 2009. 49f. 2009. Dissertação [Licenciatura em Letras - LIBRAS na modalidade à distância] - Universidade Federal de Santa Catarina, Florianópolis, 2009.

VIGOTSKI, L. S. Fundamentos de Defectologia. Obras Escogidas, vol. V, Madrid. Visor Dias, S.A. 1997.

VIGOTSKI, L. S. A construção do pensamento e da linguagem. Martins Fontes. São Paulo. 2001. 